B. R. Gedulin · P. Smith - K. S. Prickett $\cdot$ M. Tryon •

S. Barnhill · J. Reynolds · L. L. Nielsen · D. G. Parkes •

A. A. Young

\title{
Dose-response for glycaemic and metabolic changes 28 days after single injection of long-acting release exenatide in diabetic fatty Zucker rats
}

Received: 20 October 2004 / Accepted: 9 February 2005 / Published online: 25 May 2005

(C) Springer-Verlag 2005

\begin{abstract}
Aims/hypothesis: Exenatide (exendin-4) injected subcutaneously twice daily reduces glycaemic deterioration in diabetic fatty Zucker (ZDF) rats and reduces $\mathrm{HbA}_{1} \mathrm{c}$ in humans with type 2 diabetes. Because tachyphylaxis may develop with continuous peptide exposure, we examined the activity of a long-acting-release (LAR) formulation of exenatide on $\mathrm{HbA}_{1} \mathrm{c}$, insulin sensitivity and beta cell secretion in ZDF rats. Methods: Single subcutaneous injections of a poly-lactide-glycolide microsphere suspension ( $3 \%$ peptide) containing $0,1,10,100,1,000$, 3,000 or $9,000 \mu \mathrm{g}$ exenatide were administered to 9-weekold $\mathrm{ZDF}$ rats with matched initial $\mathrm{HbA}_{1} \mathrm{c}$ values $(n=7$ rats/ group). Results: In contrast to the progressive $3.22 \pm$ $0.42 \%$ increase in $\mathrm{HbA}_{1} \mathrm{c}$ in control ZDF rats observed over 28 days, single exenatide-LAR injections dose-proportionally prevented such glycaemic deterioration (median effective dose $74 \mu \mathrm{g} \pm 0.1 \mathrm{log}$ per rat; median effective concentration $52 \mathrm{pmol} / 1 \pm 0.06 \mathrm{log}$ ). Hyperinsulinaemic-euglycaemic clamp procedures incorporating an intraclamp glucose challenge performed 28 days after treatment revealed increases in beta cell response to the glucose challenge at lower exenatide-LAR doses, and up to a 2.1fold increase in insulin sensitivity at higher exenatideLAR doses. Conclusions/interpretation: The finding that a single dose of exenatide-LAR enhanced glucose control for 28 days in the ZDF rat model of type 2 diabetes suggests that tachyphylaxis is unlikely to be a feature of exenatide-LAR preparations, and supports further clinical exploration.
\end{abstract}

Keywords AC2993 - Diabetic fatty Zucker (ZDF) rats · Exenatide-LAR $\cdot$ Exendin-4 $\cdot$ Type 2 diabetes

B. R. Gedulin · P. Smith · K. S. Prickett · M. Tryon ·

S. Barnhill · J. Reynolds · L. L. Nielsen · D. G. Parkes

A. A. Young $(\bowtie)$

Amylin Pharmaceuticals,

9360 Towne Centre Dr., Suite 110,

San Diego, CA, 92121, USA

e-mail: ayoung@amylin.com

Tel.: +1-858-6427122

Fax: +1-858-3341122
Abbreviations $\mathrm{EC}_{50}$ : median effective concentration $\mathrm{ED}_{50}$ : median effective dose $\cdot$ GLP-1: glucagon-like peptide-1 $\cdot$ LAR: long-acting-release $\cdot$ ZDF rat: diabetic fatty Zucker rat

\section{Introduction}

Exenatide (exendin-4) is a 39-amino acid peptide originally isolated from the salivary secretions of Heloderma suspectum (Gila monster) [1]. Although distinct from lizard glucagon-like peptide-1 (GLP-1) [2], exendin-4 has been shown to be an agonist at pancreatic GLP-1 receptors in vitro [3]. Exenatide is reported to share many glucoregulatory actions with GLP-1, including glucose-dependent insulinotropic, glucagonostatic, gastric slowing, and satiogenic effects [4]. It has also been reported that exenatide promotes beta cell proliferation and islet neogenesis in rats [5] and restores a normal insulin-secretory pattern in humans [6].

Exenatide is currently being explored (and has recently been approved in the USA) as a therapy in patients with type 2 diabetes mellitus [4], in whom twice daily injections for 5 months reduced $\mathrm{HbA}_{1} \mathrm{c}$ by $\sim 1.0 \%$ [7]. A sustainedrelease formulation could enhance patient convenience, reduce the need for injection, and improve compliance and control of glycaemia. However, tachyphylaxis (diminution of response) sometimes occurs when hormones normally secreted in a pulsatile manner are continuously present. For sustained-release or long-acting-release (LAR) formulations of exenatide and other incretin mimetics, it is therefore important to determine the biological response to such continuously present peptides.

In the present experiments, we observed glycaemic and other metabolic changes in the ZDF rat model of type 2 diabetes mellitus for 28 days after a single subcutaneous injection of exenatide-LAR. We show that, compared with results previously reported for twice-daily injections, the glucose-lowering effect was maintained. We additionally assessed the relative roles of enhanced beta cell function versus changes in insulin sensitivity to the overall gly- 
caemic improvement, and show that, at different parts of the exenatide-LAR dose range, both contributed.

\section{Materials and methods}

Animals Male diabetic fatty Zucker rats (ZDF/Gmi-fa/fa) obtained at $59 \pm 2$ days of age $(359 \pm 28 \mathrm{~g})$ from Charles River Laboratories (Wilmington, MA, USA), were housed at $22 \pm 1^{\circ} \mathrm{C}$ in a $12: 12 \mathrm{~h}$ dark : light cycle, were fed (highfat rodent diet 5008; Teklad, Madison, WI, USA) and watered ad libitum, and were acclimatised for $\sim 1$ week before treatment. Animals were distributed equally into seven groups with matched baseline $\mathrm{HbA}_{1} \mathrm{c}(n=7$ rats/ group, $n=14$ for vehicle controls). Principles of laboratory animal care (NIH Publication no. 85-23, revised 1985; http://grants1.nih.gov/grants/olaw/references/phspol.htm) were followed, and the protocol was approved by an institutional animal welfare committee.

Exenatide treatment Exenatide 3\%, sucrose 2\% and $\left(\mathrm{NH}_{4}\right)$ ${ }_{2} \mathrm{SO}_{4} 0.3 \%$ were formulated in poly-lactide-glycolide microspheres suspended in ProLease diluent (Alkermes, Cambridge, MA, USA), $1 \mathrm{ml} / 30-60 \mathrm{mg}$ microspheres. Rats were injected with a single exenatide-LAR dose of 0 , $1,10,100,1,000,3,000$ or $9,000 \mu \mathrm{g}$, subcutaneously.

Blood samples Blood samples were taken from the topically anaesthetised tails of overnight-fasted rats 10, 20 and 28 days after exenatide-LAR injection for measurement of glucose (Cobas Mira; Roche Diagnostics, Indianapolis, IN, USA) and $\mathrm{HbA}_{1} \mathrm{c}$ in a system using a specific monoclonal antibody with a turbidimetric readout (DCA2000 analyser; Bayer, Elkhart, IN, USA; CV 2.2\%, traceable to the DCCT reference method). Plasma exenatide concentrations were measured by Amylin Pharmaceuticals (San Diego, CA, USA) using a previously published immunoenzymetric assay [8].

Hyperinsulinaemic-euglycaemic clamp procedure Insulin sensitivity was assessed from the glucose infusion rate required to maintain euglycaemia in clamp procedures performed 28 days after exenatide-LAR injection. Rats that had fasted overnight were anaesthetised with isoflurane. Since stress responses confound metabolic measures (e.g. glucose infusion rate, plasma glucose and plasma lactate), data were included only from preparations in which mean arterial pressure (Biopac Systems, Santa Barbara, CA, USA) was maintained above $80 \mathrm{mmHg}(n=12,5,6$, $6,7,5,3$ for $0,1,10,100,1,000,3,000$ and 9,000 $\mu \mathrm{g}$ exenatide-LAR treatment groups, respectively). Primedcontinuous insulin (Humulin R; Eli Lilly, Indianapolis, IN, USA; $180 \mathrm{nmol} / \mathrm{kg}+0.6 \mathrm{nmol} \cdot \mathrm{kg}^{-1} \cdot \mathrm{min}^{-1}[90 \mathrm{U} / \mathrm{kg}$ $\left.+100 \mathrm{mU} \cdot \mathrm{kg}^{-1} \cdot \mathrm{min}^{-1}\right]$ ) was infused from -60 to $+180 \mathrm{~min}$ (plasma concentration $\sim 1 \mathrm{nmol} / \mathrm{l}$ ). Intravenous infusions of $20 \%$ glucose were varied according to 10 -min arterial glucose/lactate measurements (YSI 2300 STAT analyser; YSI, Yellow Springs, OH, USA) to maintain glucose concentrations at $5.8 \mathrm{mmol} / \mathrm{l}$ for $180 \mathrm{~min}$.
Intraclamp IVGTT In rats treated with $0,1,10$ and $100 \mu \mathrm{g}$ exenatide-LAR, beta cell secretory function was assessed from changes in plasma C-peptide (Rat C-peptide RIA, kit RCP-21K; Linco, St Charles, MO, USA). At $180 \mathrm{~min}$, insulin infusions were interrupted, glucose infusions were maintained at the prevailing rate, and an additional $1 \mathrm{~g} / \mathrm{kg}$ intravenous bolus was infused. Plasma C-peptide was measured 5, 10, 30, 60 and 90 min after the bolus.

Statistical analyses Sigmoidal curve fitting was performed using GraphPad Prism software version 4.0 for Windows (GraphPad Software, San Diego, CA, USA). The statistical significance of the treatment effect was tested by oneway ANOVA, with Tukey-Kramer multiple comparison post-test Student's $t$-test for pairwise comparisons. We considered $p$ values $\leq 0.05$ to be significant. Values are means \pm SEM unless otherwise indicated.

\section{Results}

Plasma exenatide After a single injection of exenatideLAR, plasma exenatide concentrations were sustained for at least 28 days. Plasma concentrations still increased with time at higher exenatide-LAR doses, but otherwise appeared to be unaffected by time (Fig. 1a). The plasma concentration averaged over 28 days was monotonically related to dose (Fig. 1b). Mean concentrations shown in Fig. 1 were used to construct the concentration-response curves shown in other figures.

$H b A_{1} c$ In vehicle-treated control ZDF rats, $\mathrm{HbA}_{1} \mathrm{c}$ progressively increased over 28 days, as previously described in this disease model [9]. In contrast, exenatide-LAR dosedependently prevented the expected increase in $\mathrm{HbA}_{1} \mathrm{c}$ (drug effect $p<0.0001$; ANOVA, at 10, 20 and 28 days). On each measurement day, all exenatide-LAR doses over $10 \mu \mathrm{g}$ were associated with an $\mathrm{HbA}_{1} \mathrm{c}$ increment that was significantly less than control (median effective dose $\left[\mathrm{ED}_{50}\right] 74 \mu \mathrm{g} \pm 0.1 \mathrm{log}$; Fig. 2a). Mapping of mean 28-day plasma exenatide concentrations from Fig. $1 \mathrm{~b}$ enabled concentration-response analysis $\left(\mathrm{EC}_{50} 52 \mathrm{pmol} / \mathrm{l} \pm 0.06 \mathrm{log}\right.$; Fig. 2b). In Fig. 2c, the dose-response curve for change in $\mathrm{HbA}_{1} \mathrm{c}$ (percentage of increment in controls) with exenatide-LAR in the present experiments is compared with a previously reported dose-response curve in ZDF rats injected subcutaneously twice daily [9]. The glucose-lowering effect at 28 days, compared on the basis of cumulative 28-day dose, showed no diminution of effect when exenatide was delivered by the exenatide-LAR formulation compared with twice-daily injection.

Food intake and body weight Daily food intake over time, and as a dose-response curve, is shown in Fig. 3. An abrupt dose-dependent effect to inhibit food intake, greatest on the first day, declined over the ensuing week towards a steady inhibition of intake during the second, third and fourth weeks. The $\mathrm{ED}_{50}$ was $277 \mu \mathrm{g} \pm 0.17 \mathrm{log}$ for the dose-response analysis in Fig. 3b, where intake was averaged for 
a

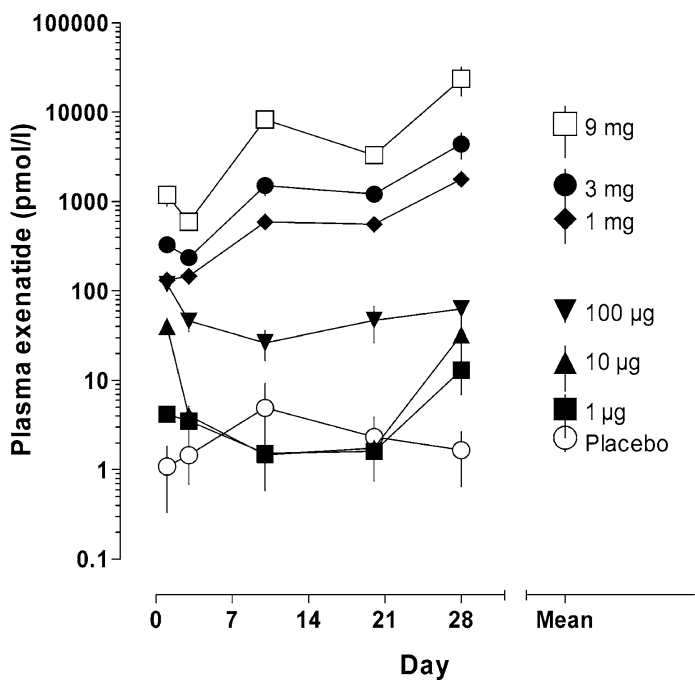

Fig. 1 Plasma exenatide concentrations after exenatide-LAR injections. a Concentration profiles for plasma exenatide for 28 days following a single subcutaneous dose. Time-weighted mean concentration is shown to the right. b Relationship between dose and plasma concentration. Large symbols are the 28-day means joined

$1-10,11-20$ and $21-28$ days. Gain in body weight with time, shown in Fig. 3c, was dose-dependently slowed for $\sim 10$ days. Thereafter, weight gain was paradoxically increased at the 10- and 100- $\mu$ g doses (at which effects on food intake were modest), and declined with higher doses (Fig. 3d), associated with anorectic responses (Fig. 3b).

Clamp studies The fasting plasma glucose concentration prior to the clamp was dose-dependently reduced by prior exenatide-LAR treatment (drug effect, $p<0.0001$, ANOVA, b

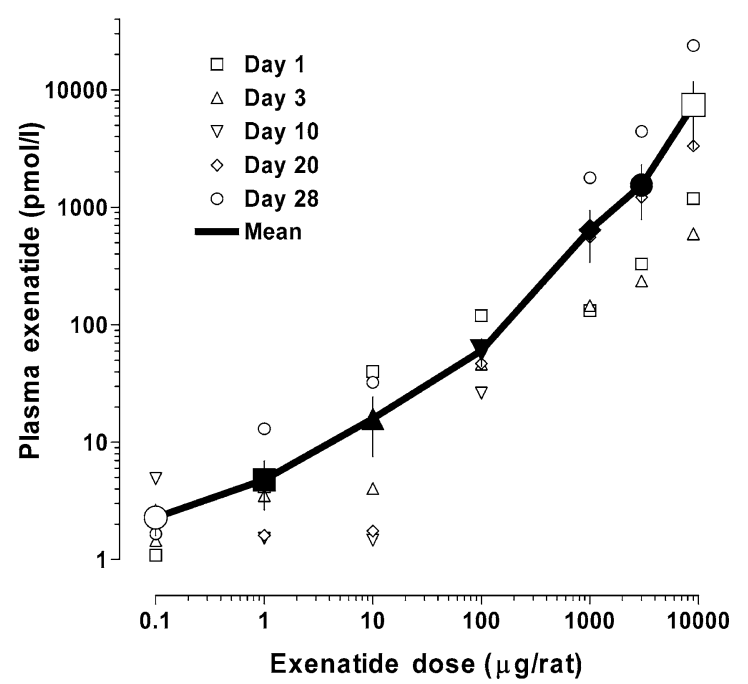

by a solid line. Placebo, open circles; $1 \mu \mathrm{g}$, filled squares, $10 \mu \mathrm{g}$, filled triangles; $100 \mu \mathrm{g}$, inverted filled triangles; $1,000 \mu \mathrm{g}$, filled diamonds; 3,000 $\mu \mathrm{g}$ filled circles; 9,000 $\mu \mathrm{g}$, open squares. All symbols are mean \pm SEM

$\mathrm{ED}_{50} 341 \mu \mathrm{g} \pm 0.39 \log$; Fig. 4a, b). Reductions were different from controls for doses over $100 \mu \mathrm{g}$. Glucose was clamped at $5.81 \mathrm{mmol} / \mathrm{l}$ with a coefficient of variation of $8.7 \%$. Dose-response analysis of the glucose infusion rate over 60-180 min of the clamp indicated a marked increase in insulin sensitivity (up to 2.1 -fold versus control). Insulin sensitisation was apparent and significant with exenatideLAR doses of $1 \mathrm{mg}$ and above (drug effect, $p<0.0001$, ANOVA, $E_{50} 403 \mu \mathrm{g} \pm 0.23$ log; Fig. 4c, d). Effects on glucose-driven C-peptide responses were apparent with

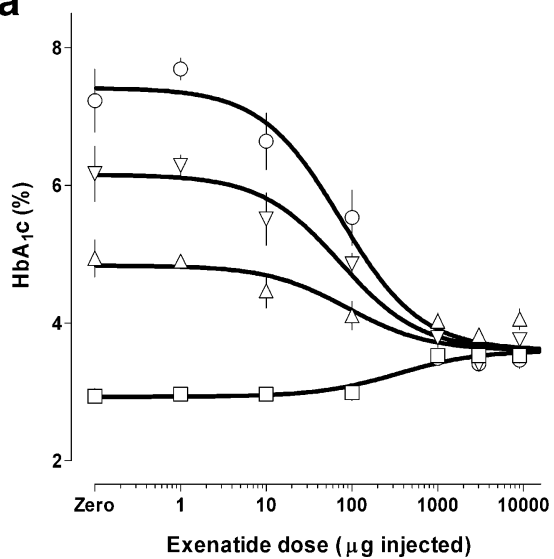

b

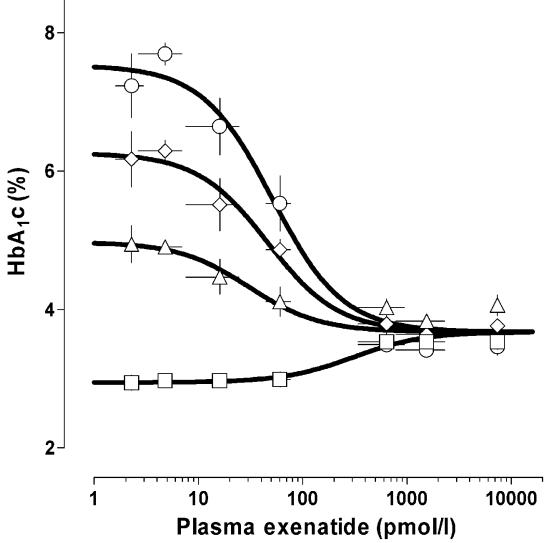

C

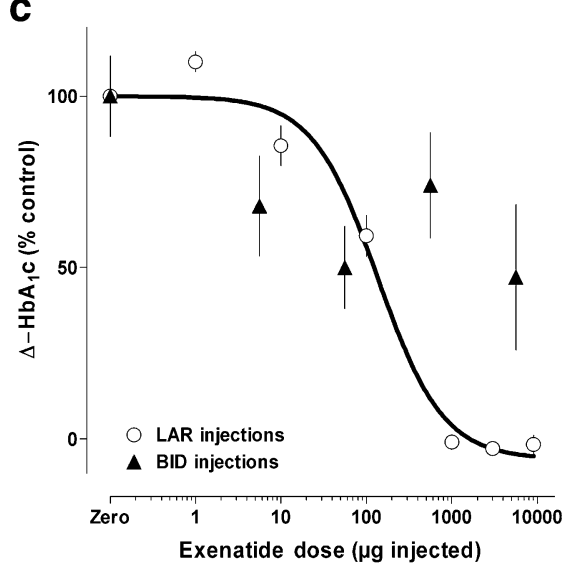

Fig. 2 Dose and concentration responses for effects of exenatideLAR on $\mathrm{HbA}_{1} \mathrm{c}$ in ZDF rats. a Dose-response curves for effect of single exenatide-LAR doses given at the expected onset of diabetes (age 9 weeks) on $\mathrm{HbA}_{1} \mathrm{c}$ measured at baseline (open squares) and 10 (open triangles), 20 (open diamonds) and 28 (open circles) days later. Animals given zero dose showed an increase in $\mathrm{HbA}_{1} \mathrm{c}$, consistent with the expected disease progression in this model. b Concentration-response curve for effect of mean 28-day plasma exenatide concentration on $\mathrm{HbA}_{1} \mathrm{c}$. The data were derived using the relationship shown in Fig. $1 \mathrm{~b}$ to remap the $x$-axis. c Comparison of effects of exenatide-LAR [represented as a single injection dose in the present study (open circles) versus cumulative 28-day twicedaily dose in a previous study (filled triangles)] on increment in $\mathrm{HbA}_{1} \mathrm{c}$ (represented as percentage of increment observed in vehicletreated controls). In all panels data are means \pm SEM 

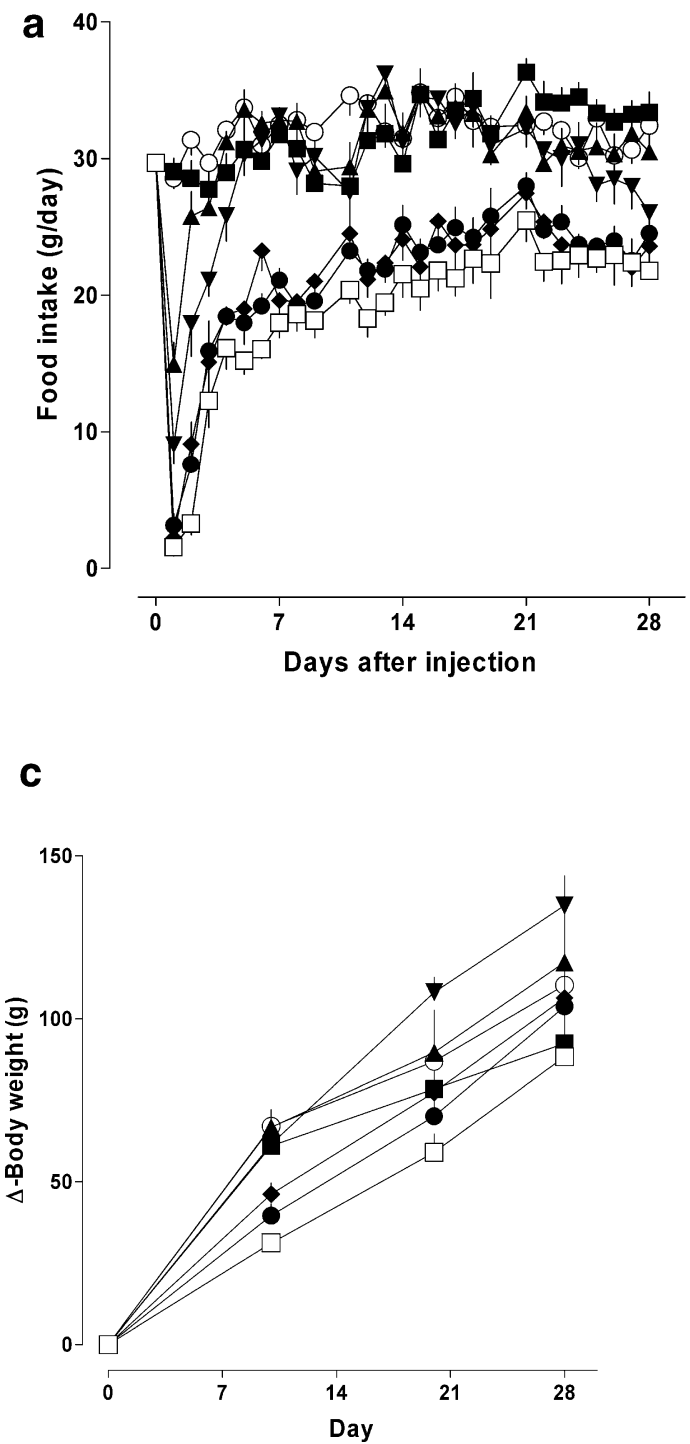

Fig. 3 Effects of exenatide-LAR on food intake and body weight gain. a Time course for inhibition of food intake following single subcutaneous exenatide-LAR injection. b Dose-response curve for mean daily intake calculated over 1-10 days (open triangles), 11-20 days (open diamonds) and 21-28 days (open circles). c Time course for increase in body weight as a function of the indicated exenatide

lower doses of exenatide-LAR (drug effect, $p<0.03$, ANOVA, $\mathrm{ED}_{50} 9.8 \mu \mathrm{g} \pm 0.31$ log; Fig. $4 \mathrm{e}, \mathrm{f}$ ).

\section{Discussion}

Exenatide was formulated into a preparation from which it was dose-proportionally released for at least 28 days. The glucose-lowering effect and potency of exenatide-LAR in ZDF rats compared favourably with results previously obtained with twice-daily injections of exenatide in a standard (saline) formulation. The absence of tachyphylaxis with exenatide-LAR is consistent with a previous preliminary report using osmotic pumps, where the antidiabetic b
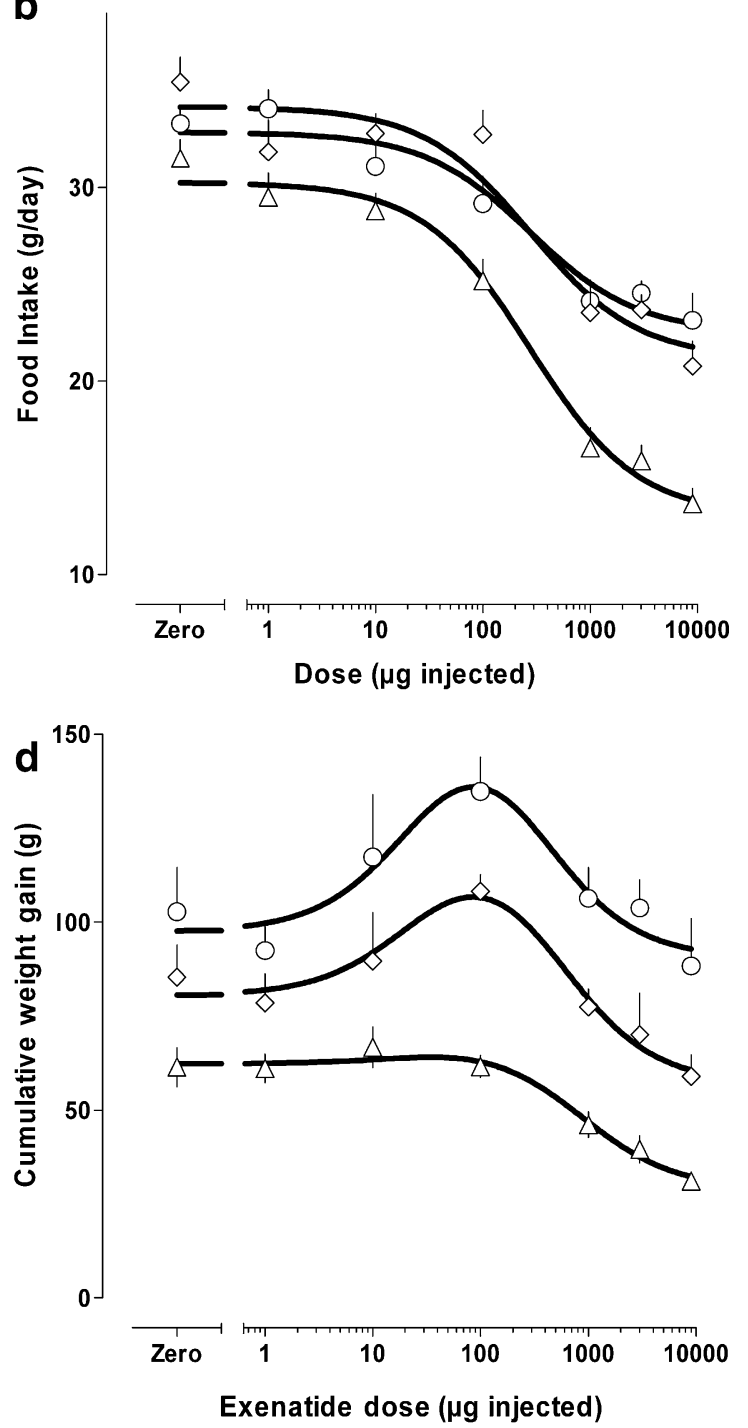

LAR doses. $\mathbf{d}$ Dose response for cumulative weight gain at 10 (open triangles), 20 (open diamonds) and 28 (open circles) days. a, c Placebo, open circles; $1 \mu \mathrm{g}$, filled squares, $10 \mu \mathrm{g}$, filled triangles; $100 \mu \mathrm{g}$, inverted filled triangles; $1,000 \mu \mathrm{g}$, filled diamonds; 3,000 $\mu \mathrm{g}$, filled circles; 9,000 $\mu \mathrm{g}$, open squares. Symbols are means \pm SEM

effect was also not diminished compared with twice-daily injections [unpublished data].

The present studies are the first to demonstrate an antidiabetic effect of a monthly injection. While LAR formulations may expand therapeutic options, the formulated drug requires a high therapeutic index since it cannot be withdrawn once injected. In clinical studies or in animal toxicology studies (where exposure was up to 300,000 times the antidiabetic dose [unpublished data]), exenatide has thus far not shown evidence of serious toxicity. A feature of exenatide that may similarly contribute a high therapeutic index is that several of its glucoregulatory actions are glucose-dependent and are overridden during hypoglycaemia [10]. A further requirement is high in vivo 
Fig. 4 Effects of 28 days of exposure to exenatide, following a single subcutaneous injection of exenatide-LAR, on: fasting (pre-clamp) plasma glucose $(\mathbf{a}, \mathbf{b})$; glucose infusion rate required to maintain $5.8 \mathrm{mmol} / \mathrm{l}$ isoglycaemia (c, d); and $\mathbf{e}, \mathbf{f}$ beta cell secretory response following an intraclamp glucose challenge at $180 \mathrm{~min}$ (reflected by changes in plasma $\mathrm{C}$-peptide concentration). Clamp data are shown in (a), (c) and (e) and derived dose-response curves are shown in (b), (d) and (f). a, c, e Placebo, open circles; $1 \mu \mathrm{g}$, filled squares; $10 \mu \mathrm{g}$, filled triangles; $100 \mu \mathrm{g}$, inverted filled triangles; $1,000 \mu \mathrm{g}$, filled diamonds; 3,000 $\mu \mathrm{g}$, filled circles; 9,000 $\mu \mathrm{g}$, open squares. Symbols are means \pm SEM
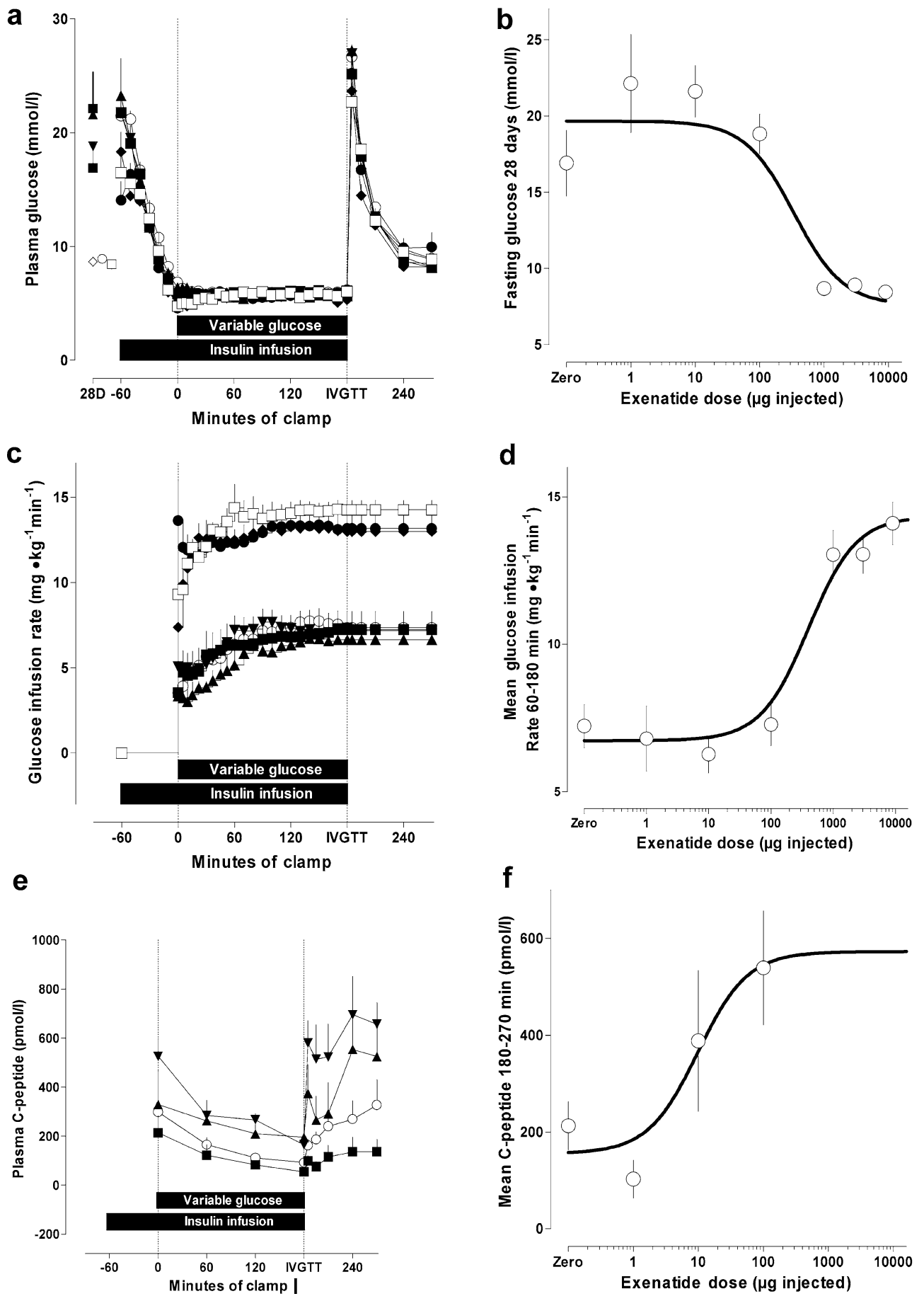

potency, sufficient to reduce injections to a practicable volume. The in vivo potency of exenatide is over 1,000 times that of GLP-1 in some animal models [9]. Similar potency is apparent in humans, in whom glucose-lowering is apparent with doses of 10-20 $\mu \mathrm{g} /$ day [7].

The clamp data in the present study suggest that glycaemic improvement at lower exenatide-LAR doses is associated with augmented beta cell secretion (as evidenced by C-peptide measurements). Improvements in islet secretory function are reported in humans administered exenatide twice daily [6]. The anatomical basis of im- proved beta cell secretion was not investigated in the present study. However, we recently showed in a related (but non-diabetic) animal model, the $f a / f a$ (fatty Zucker) rat, that relative to changes expected with (and normalised for) the observed increase in insulin sensitivity, there had been an increase in beta cell mass [11]. These results were consistent with previous reports of induction of beta cell neogenesis and differentiation $[5,12,13]$. The ability to stimulate beta cell neogenesis was not associated with the promotion of proliferative lesions in a 2-year rodent safety study [14]. 
In the present study, higher exenatide-LAR doses were associated with an improvement in insulin sensitivity, comparable in magnitude to previous observations in ZDF rats [9] and falfa rats [11]. The combination of augmented beta cell secretion and augmented insulin sensitivity can account for the substantial dose-dependent reductions in long-term glycaemic indicators shown in Fig. 2. The benefit of such a glycaemic change, on longevity for example, has not been determined in the ZDF model. However, in the chronic safety study cited above [14], non-diabetic Sprague-Dawley rats showed an $\sim 3$-fold increase in individuals surviving to 2 years of age.

Food intake was monotonically linked to exenatide-LAR dose and to mean plasma concentration in the present study. It does not necessarily follow, however, that increases in insulin sensitivity were a result of decreases in food intake. In previous studies using controls pair-fed the same number of calories as exenatide-treated animals consumed, there was an effect of exenatide to increase insulin sensitivity independently of caloric intake or glycaemic change [unpublished data].

The relationship between exenatide-LAR and weight gain in the present study was initially sigmoid but became progressively bell-shaped with time, and was somewhat different in character to the food intake response. A similar pattern has been noted previously with exenatide in diabetic ZDF rats, where lower doses promote weight gain. This could reflect an augmentation of insulin action, which the anorectic effect overrides at higher doses. However, a dissociation between food intake and weight gain has also been observed in ZDF rats treated with PYY[3-36], which does not have an insulinotropic effect [15]. In that study, weight gain with glucose-lowering treatment was associated with reversal of urinary glucose loss. Weight gain with exenatide or with PYY[3-36] appears to be a feature in diabetic models that is associated with the reversal of glycosuria. Whatever the mechanism, the disparity between dose responses for weight gain versus responses for insulin secretion, insulin sensitivity and glucose-lowering effect indicates that the latter are not being driven by change in body weight.

In summary, compared with effects seen with periodic injections, the glucose-lowering effect and the potency of continuously present exenatide-LAR is maintained in the ZDF rat model of type 2 diabetes. These findings support the further exploration and development of such formulations for the treatment of human diabetes.

Duality of interest

All authors are employees of Amylin Pharmaceuticals, the developers of exenatide, and may own stock in this company.

Acknowledgements We thank T. Yeoh (Alkermes) for assistance with the exenatide-LAR formulation.

\section{References}

1. Eng J, Kleinman WA, Singh L, Singh G, Raufman JP (1992) Isolation and characterization of exendin-4, an exendin-3 analogue, from Heloderma suspectum venom. Further evidence for an exendin receptor on dispersed acini from guinea pig pancreas. J Biol Chem 267:7402-7405

2. Chen YQE, Drucker DJ (1997) Tissue-specific expression of unique mRNAs that encode proglucagon-derived peptides or exendin 4 in the lizard. J Biol Chem 272:4108-4115

3. Goke R, Fehmann HC, Linn T et al (1993) Exendin-4 is a high potency agonist and truncated exendin-(9-39)-amide an antagonist at the glucagon-like peptide 1-(7-36)-amide receptor of insulin-secreting beta-cells. J Biol Chem 268:19650-19655

4. Nielsen LL, Young AA, Parkes DG (2004) Pharmacology of exenatide (synthetic exendin-4): a potential therapeutic for improved glycemic control of type 2 diabetes. Regul Pept 117:7788

5. Xu G, Stoffers DA, Habener JF, Bonner-Weir S (1999) Exendin-4 stimulates both beta-cell replication and neogenesis, resulting in increased beta-cell mass and improved glucose tolerance in diabetic rats. Diabetes 48:2270-2276

6. Fehse FC, Trautmann ME, Holst JJ et al (2004) Effects of exenatide on first and second phase insulin secretion in response to intravenous glucose in subjects with type 2 diabetes. Diabetes 53[Suppl 2]:A82. Abstract 351-OR

7. Buse JB, Henry RR, Han J, Kim DD, Fineman MS, Baron AD (2004) Effects of exenatide (exendin-4) on glycemic control over 30 weeks in sulfonylurea-treated patients with type 2 diabetes. Diabetes Care 27:2628-2635

8. Petrella E, Waterhouse T, Estrada-Stolpe DHR (2001) Development and validation of an immunoenzymetric assay (IEMA) for the quantitation of AC2993 (exendin-4) in plasma and its application to preclinical toxicity evaluations. AAPS PharmSci 3(3)

9. Young AA, Gedulin BR, Bhavsar S et al (1999) Glucoselowering and insulin-sensitising actions of exendin-4: studies in obese diabetic $(o b / o b, d b / d b)$ mice, diabetic Fatty Zucker rats and diabetic rhesus monkeys (Macaca mulatta). Diabetes 48:1026-1034

10. Degn KB, Brock B, Juhl CB et al (2004) Effect of intravenous infusion of exenatide (synthetic exendin-4) on glucose-dependent insulin secretion and counterregulation during hypoglycemia. Diabetes 53:2397-2403

11. Gedulin BR, Nikoulina SE, Smith PA et al (2005) Exenatide (exendin-4) improves insulin sensitivity and $\beta$-cell mass in insulin-resistant obese $f a / f a$ Zucker rats independent of glycemia and body weight. Endocrinology 146:2069-2076

12. Zhou J, Pineyro MA, Wang X, Doyle ME, Egan JM (2002) Exendin-4 differentiation of a human pancreatic duct cell line into endocrine cells: involvement of PDX-1 and HNF3beta transcription factors. J Cell Physiol 192:304-314

13. Zhou J, Wang X, Pineyro MA, Egan JM (1999) Glucagon-like peptide 1 and exendin-4 convert pancreatic AR42J cells into glucagon- and insulin-producing cells. Diabetes 48:2358-2366

14. Hiles R, Carpenter T, Serota D et al (2004) Exenatide does not cause pancreatic islet cell proliferative lesions in rats and mice following 2-year exposure. Diabetes 53[Suppl 2]:A380 (Abstract)

15. Pittner RA, Moore CX, Bhavsar SP et al (2004) Effects of PYY [3-36] in rodent models of diabetes and obesity. Int J Obes Relat Metab Disord 28:963-971 